\title{
INTERCEPTAÇÃO DE LUZ E ÍNDICE DE ÁREA FOLIAR EM RELAÇÃO A ALTURA DO DOSSEL DE GRAMÍNEAS FORRAGEIRAS
}

\author{
GALZERANO, Leandro ${ }^{1 *}$ \\ MALHEIROS, Euclides Braga ${ }^{1}$ \\ MORGADO, Eliane da Silva ${ }^{1}$ \\ RUGGIERI, Ana Claudia ${ }^{1}$
}

RESUMO: O objetivo deste trabalho foi determinar a existência de relação entre a interceptação da radiação fotosinteticamente ativa (IRFA) e o índice de área foliar (IAF) com a altura do dossel de gramíneas forrageiras. Estudou-se três capins de diferentes gêneros: capim-florona, um capim do gênero Cynodon, o capim-áries, um Panicum e o capim-braquiária decumbens, do gênero Brachiaria. Em cada capim foi utilizada uma área experimental de $35,0 \mathrm{~m}^{2}$. O experimento foi conduzido na Faculdade de Ciências Agrárias e Veterinárias/ Unesp, Campus de Jaboticabal, SP. Os capins foram mantido sob cortes a $5 \mathrm{~cm}$ do solo a cada 28 dias. Foram tomados 15 pontos amostrais sobre o dossel dos capins em fevereiro de 2010 quando os capins áries e Brachiaria decumbens estavam com 25 dias de rebrotação e o capim-florona com 24 dias de rebrotação, todos no terceiro corte. As variáveis avaliadas foram: altura do dossel, determinada com uso de régua graduada em centímetro; interceptação da radiação fotossinteticamente ativa e índice de área foliar, aferidos com sensor específico (AccuPAR Model LP - 80 PAR/LAI ceptometer). As três variáveis foram registradas no mesmo ponto amostrado. Os dados foram submetidos à análise de regressão e os resultados demonstram que a altura do dossel se correspondente positivamente com a interceptação da radiação fotossinteticamente ativa e o índice de área foliar em gramíneas forrageiras.

Palavras-chave: Brachiaria. Cynodon. Dossel. Ecofisiologia de forrageiras. Panicum Urochloa.

SUMMARY: The objetive of this study was to determine the existence of a relationship between the interception of photosynthetically active radiation (IPAR) and leaf area index (LAI) with canopy height of forage grasses. It was studied three different grasses: florona grass, a Cynodon; áries grass, a Panicum and Braquiária decumbens grass, a Brachiaria. It was used a total area of $35 \mathrm{~m}^{2}$ per each grass. The experiment was conducted at Faculdade de Ciências Agrárias e Veterinárias/ Unesp de Jaboticabal, SP, Brazil. The grasses were clipped to $5 \mathrm{~cm}$ stubble height at every 28 days of regrowth. It was taken 15 canopy sampling points when áries and Brachiaria grasses were at 25 days of regrowth and florona 24 days, at the third clipping period. The variables evaluated were: canopy height, determined by use of a ruler graduated in centimeters; interception of photosynthetically active radiation and leaf area index, measured with specific sensor (Model AccuPar Lp - 80 PAR/LAI ceptometer). The three measures were taken at the same canopy point. Data were submitted to regression analysis and the results show that the canopy height is positively correlated with the corresponding IPAR and LAI in grasses.

Keywords: Brachiaria, Canopy. Cynodon. Forage ecophysiology. Panicum. Urochloa.

\section{INTRODUÇÃO}

As pastagens, devido seu baixo custo de produção em relação aos concentrados, representam à forma mais prática e econômica de alimentação de bovinos e constituem a base de sustentação da pecuária do Brasil (CUNHA et al., 2007). No Brasil, não há registro preciso de onde e de como foi introduzido o gênero Cynodon. O fato é que, possivelmente, isto se deu por iniciativa de produtores e pesquisadores, para realizar avaliações comportamentais nas condições brasileiras (VILELA; ALVIN, 1998).

\footnotetext{
${ }^{1}$ Faculdade de Ciências Agrárias e Veterinárias, Universidade Estadual Paulista - Unesp, 14884-900, Jaboticabal-SP, Brasil. *E-mail: galzeranorural@yahoo.com.br
} 
O capim Áries é híbrido obtido do cruzamento de dois acessos de Panicum maximum, de ciclo perene, planta cespitosa com grande potencial de perfilhamento, com colmo delgado, folhas estreitas, sem pilosidade e de coloração verde claro. Dentre as gramíneas recomendadas para equinos para pastagem o capim Áries destaca-se como a principal gramínea hoje disponível no mercado, pois tolera solos moderadamente húmidos, é bem aceita pela sua palatabilidade e muito bem consumida pelos equinos (VILELA, 2009). O capim braquiária é o mais encontrado no Brasil, pois adapta-se bem em diversos climas e classes de solos, além de apresentar boa palatabilidade, persistência e bom valor nutritivo. As pastagens, devido ao seu baixo custo de produção em relação aos concentrados, representam à forma mais prática e econômica de alimentação de bovinos e constituem a base de sustentação da pecuária do Brasil (CUNHA et al., 2007).

Pesquisas sobre as respostas ecofisiológicas são de grande importância para o manejo de pastagens de gramíneas. A interceptação de radiação fotossinteticamente ativa (IRFA, 400-700 nm) é um fator da biofísica fundamental dentro do programa trófico das plantas (BROUGHAM, 1958) e está diretamente relacionada com a estrutura do dossel. A fotossíntese á e força motriz do crescimento vegetal e produção animal e é dependente da área e eficiência do tecido verde da planta. Estudos sobre estratégias de pastejo com plantas forrageiras têm se concentrado na interceptação de luz bem como no principal aparato captador de luz, a área foliar, quanto a sua forma, distribuição e mobilidade em relação a radiação recebida (MANNETJE, 2002). Watson (1947) introduziu na ciência da pastagem o conceito de índice de área foliar como sendo a área de uma das faces das folhas, dividida pela área de solo que ocupam, no entanto, os primeiros estudos relacionando IAF com plantas forrageiras foram realizados por Brougham (1958) que constatou que o IAF para máxima interceptação da radiação depende de vários fatores como espécie forrageira, elevação do sol, orientação das folhas, se planófilas, eretófilas assim como o formato, se mais estreitas ou largas.

A altura do dossel forrageiro pode ser facilmente relacionada com a interceptação da radiação fotossinteticamente ativa (IRFA) e o índice de área foliar (IAF) pois trata-se de é uma medida de fácil e rápida obtenção. Diante do exposto, objetivou-se com este estudo avaliar a relação entre a IRFA e o IAF com a altura do dossel de gramíneas forrageiras mantidas sob corte.

\section{MATERIAL E MÉTODOS}

O experimento foi conduzido na Faculdade de Ciências Agrárias e Veterinárias da Unesp, Campus de Jaboticabal, SP, localizada a $21^{\circ} 15^{\prime} 22^{\prime \prime}$, de latitude sul, longitude de $48^{\circ} 18^{\prime} 58^{\prime}$ ' $\mathrm{W}$, a uma altitude de $595 \mathrm{~m}$. O solo da área experimental foi classificado como Latossolo Vermelho Distrófico, textura argilosa, horizonte A moderado, caulinítico hipoférrico com relevo suave ondulado (EMBRAPA, 2006). Uma análise da camada arável do solo realizada em novembro de 2009 , indicou as seguintes propriedades químicas: Ca: 45; Mg: 12; K: 1,4 mmol.dm ${ }^{-3}$; P (resina): $24 \mathrm{mg} \cdot \mathrm{dm}^{-3} ; \mathrm{MO}: 20 \mathrm{~g} \cdot \mathrm{dm}^{-3} ; \mathrm{pH}$ $\left(\mathrm{CaCl}_{2}\right): 5,8$. O clima de Jaboticabal, de acordo com a classificação de Köppen é classificado como tropical do tipo Aw, mesotérmico com verão úmido e inverno seco. Os dados agrometeorológicos 
registrados durante o período experimental, referentes à temperatura do ar, precipitação pluviométrica, número de dias com chuva e insolação foram obtidos junto a Estação de Agrometeorologia da Unesp, Campus de Jaboticabal, distante aproximadamente 1,0 km da área experimental (Tabela 1).

Tabela 1: Médias de temperatura média do ar, precipitação pluvial, número de dias com chuva e insolação durante novembro de 2009 a fevereiro de 2010.

\begin{tabular}{lcccc}
\hline \multicolumn{1}{c}{ Mês } & $\begin{array}{c}\text { Temperatura } \\
\text { média do ar }\left({ }^{\mathbf{0}} \mathbf{C}\right)\end{array}$ & $\begin{array}{c}\text { Precipitação } \\
\text { pluvial }(\mathbf{m m})\end{array}$ & $\begin{array}{c}\text { Número de dias } \\
\text { com chuva }\end{array}$ & $\begin{array}{c}\text { Insolação } \\
(\text { h.mês } \mathbf{1})\end{array}$ \\
\hline Novembro/2009 & 25,5 & 163,3 & 15 & 202,4 \\
Dezembro/2009 & 24,1 & 383,7 & 20 & 152,9 \\
Janeiro/2010 & 24,4 & 240,7 & 20 & 154,8 \\
Fevereiro/2010 & 25,3 & 150,7 & 14 & 215,7 \\
\hline
\end{tabular}

Estudaram-se três capins de diferentes gêneros: capim-florona, um capim do gênero Cynodon, o capim-áries, um Panicum e o capim-braquiária decumbens, do gênero Brachiaria. Em cada capim foi utilizada uma área experimental de $35,0 \mathrm{~m}^{2}$. Os capins foram mantido sob cortes a $5 \mathrm{~cm}$ do solo a cada 28 dias e a adubação consistiu na aplicação de $100 \mathrm{~kg} \cdot \mathrm{ha}^{-1} \cdot \mathrm{ano}^{-1} \mathrm{de} \mathrm{N}$ na forma de Uréia, $30 \mathrm{~kg} \cdot \mathrm{ha}^{-1} \cdot \mathrm{ano}^{-1} \mathrm{de}$ $\mathrm{P}_{2} \mathrm{O}_{5}$ na forma de Superfosfato Simples e $100 \mathrm{~kg} \cdot \mathrm{ha}^{-1} \cdot \mathrm{ano}^{-1}$ de $\mathrm{K}_{2} \mathrm{O}$ na forma de Cloreto de Potássio aplicados em dose única em dezembro de 2009 após realização do primeiro corte, a fim de garantir níveis satisfatórios de fertilidade para desenvolvimento das plantas. Para realização deste estudo foram tomados 15 pontos amostrais sobre o dossel dos capins em fevereiro de 2010 quando os capins áries e braquiária decumbens estavam com 25 dias de rebrotação e o capim-florona com 24 dias de rebrotação, todos no terceiro corte. No primeiro e segundo cortes não foram realizadas medições nos capins, esses cortes serviram para imposição das alturas de rebrote aos capins. As variáveis avaliadas foram: altura do dossel, interceptação da radiação fotossinteticamente ativa (IRFA) e índice de área foliar (IAF) do mesmo ponto amostrado. A altura do dossel foi determinada com uso de régua graduada em centímetros. A IRFA e o IAF foram estimados com o aparelho analisador de dossel - AccuPAR Model LP - 80 PAR/LAI (Decagon devices ${ }^{\circledR}$ ) para esta faixa espectral da radiação solar $(400-700 \mathrm{~nm})$. Imediatamente após medida a altura média do dossel, no mesmo ponto amostrado foi estimada a IRFA e o IAF. Os dados foram submetidos à análise de regressão.

\section{RESULTADOS E DISCUSSÃO}

Na Figura 1, pode-se observar a relação entre altura do dossel e a interceptação de RFA do capimflorona, a qual explicou $86 \%$ variabilidade total $\left(R^{2}=0,86\right)$. A interceptação de RFA máxima encontrada neste trabalho de 83,0\% do capim-florona foi alcançada em $41,0 \mathrm{~cm}$ de altura do dossel. Fagundes et al., (1999) e Pinto et al., (2001), encontraram alturas inferiores para interceptação de aproximadamente 95\% de RFA trabalhando com o Cynodon, capim-tifton-85 pastejado por ovinos em regime de lotação contínua. 
Figura 1. Relação entre altura do dossel e interceptação da radiação fotossinteticamente ativa em capimflorona.

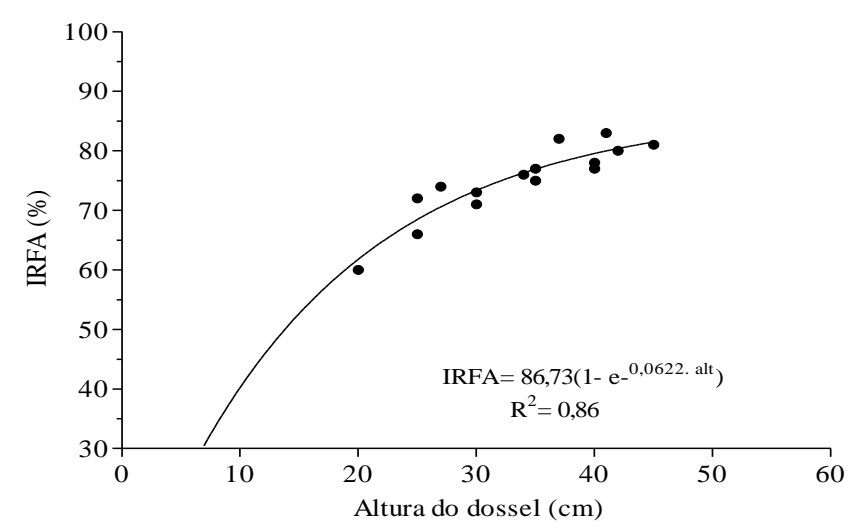

Quanto ao IAF, na Figura 2, pode-se observar a relação entre altura do dossel e o índice de área foliar do capim-florona, a qual explicou $88 \%$ variabilidade total $\left(\mathrm{R}^{2}=0,88\right)$. O índice de área foliar máximo registrado neste trabalho de 3,26 foi alcançado em $45,0 \mathrm{~cm}$ de altura do dossel do capim-florona. Fagundes et al., (1999) e Pinto et al., (2001), encontraram valores semelhantes de IAF com alturas menores trabalhando com o Cynodon capim-tifton-85 pastejado por ovinos em regime de lotação contínua. A maior altura do dossel neste estudo evidencia que o crescimento livre, sem competição, resulta em maiores alturas do dossel em relação a dosséis estabilizados e mantidos sob pastejo (GALZERANO, et al., 2008).

Figura 2. Relação entre altura do dossel e índice de área foliar em capim-florona.

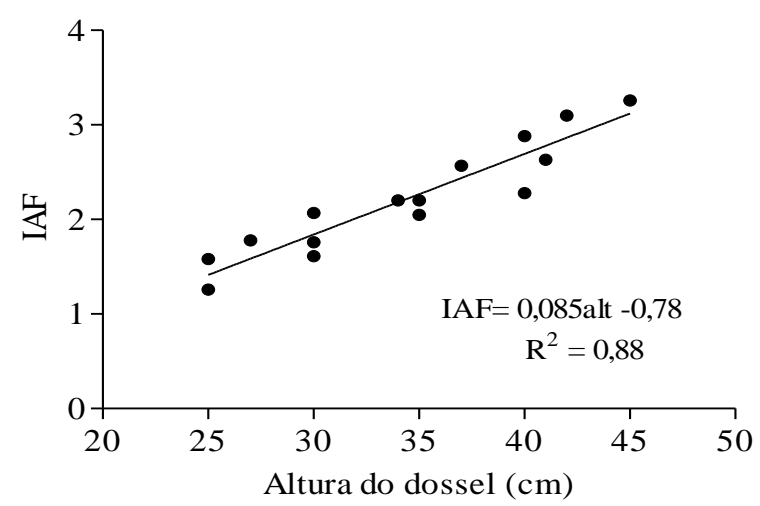

$\mathrm{Na}$ Figura 3, encontra-se a relação entre altura do dossel e a interceptação da radiação fotossinteticamente ativa em capim-áries. A relação entre altura e IRFA resultou em equação linear que explicou $79 \%$ variabilidade total $\left(\mathrm{R}^{2}=0,79\right)$. O Valor máximo de IRFA registrado foi de $89 \%$ aos $50 \mathrm{~cm}$ de altura do dossel. 
Figura 3. Relação entre altura do dossel e interceptação da radiação fotossinteticamente ativa em capimáries.

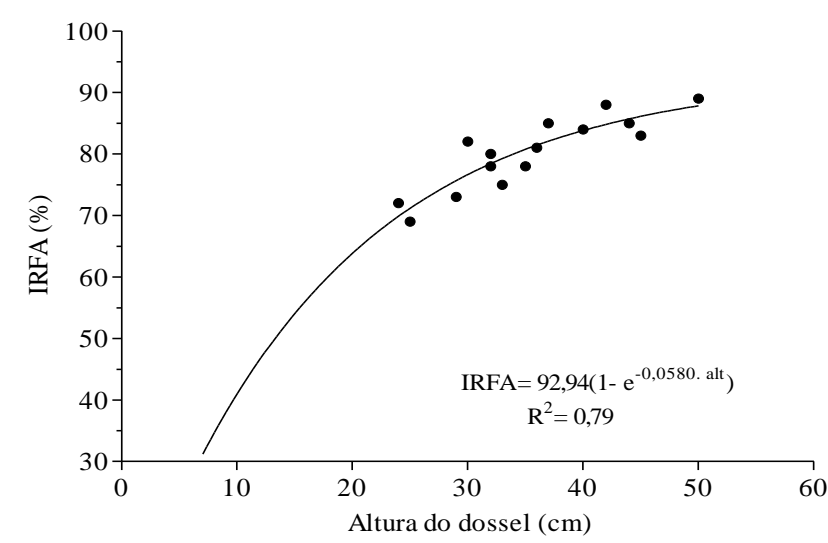

Quando a altura do dossel do capim-áries foi relacionada com o IAF (Figura 4), a equação gerada explicou $76 \%$ variabilidade total $\left(\mathrm{R}^{2}=0,76\right)$. Cândido et al. (2005) estudaram capim-elefante sob intensidade de pastejo rotativo, e concluíram que, na fase inicial do crescimento, há uma relação direta entre o IAF e a interceptação de luz no entanto, com o passar do tempo, há diminuição da interceptação de luz, com o aumento do IAF.

Figura 4. Relação entre altura do dossel e índice de área foliar em capim-áries.

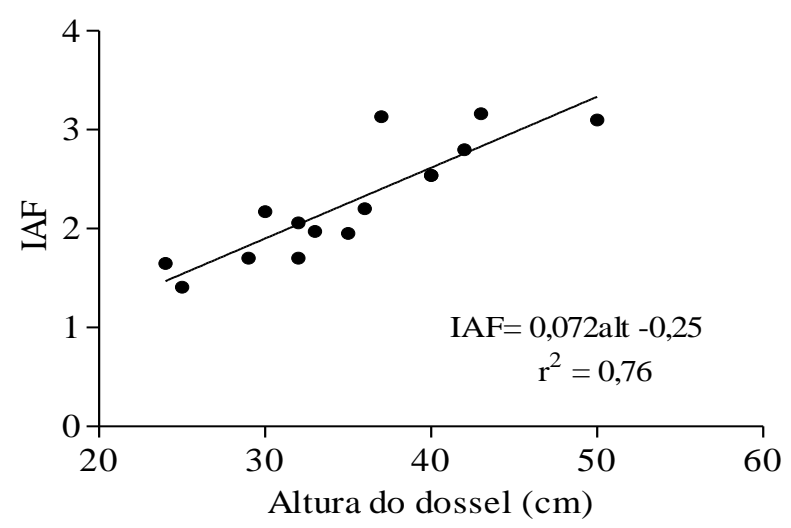

O índice de área foliar máximo encontrado neste estudo no capim-áries foi de 3,16 alcançado em 43,0 cm de altura do dossel. Aos $50 \mathrm{~cm}$ de altura, onde foi encontrada a máxima IRFA (Figura 3), o IAF foi de 3,10. Quando 95\% da radiação é interceptada, o IAF é dito como crítico (RHODES, 1971), a partir deste índice, as folhas na base do dossel passam a ser sombreadas, diminuindo a capacidade fotossintética podendo levar as folhas a morte antecipada. Já quando o dossel tem um IAF que permite interceptação de aproximadamente toda luz incidente com mínimo de auto sombreamento, e a relação entre a fotossíntese e respiração é máxima, é chamado de IAF ótimo (BROWN; BLASER, 1968). A altura do dossel encontrada neste estudo de 50,0 cm relacionada a máxima IRFA de $89 \%$ é maior que a altura de entrada para pastejo recomendada por Paulino e Teixeira (2009). 
Na Figura 5, pode-se observar a relação entre altura do dossel e a interceptação de RFA, a qual explicou $90 \%$ variabilidade total $\left(\mathrm{R}^{2}=0,90\right)$. Na prática, a altura do dossel tem sido uma característica de importância no manejo do pastejo onde trabalhos com capim do gênero Cynodon (SILVA, 2010), Panicum (SILVA, 2011) e Brachiaria sob pastejo (PEDREIRA et al., 2007) e sob corte (GALZERANO et al., 2011), foram realizados relacionando esta característica com a interceptação de $95 \%$ da luz incidente para definir o momento de interrupção do crescimento por corte ou pastejo.

Figura 5. Relação entre altura do dossel e interceptação da radiação fotossinteticamente ativa em capimbraquiária decumbens.

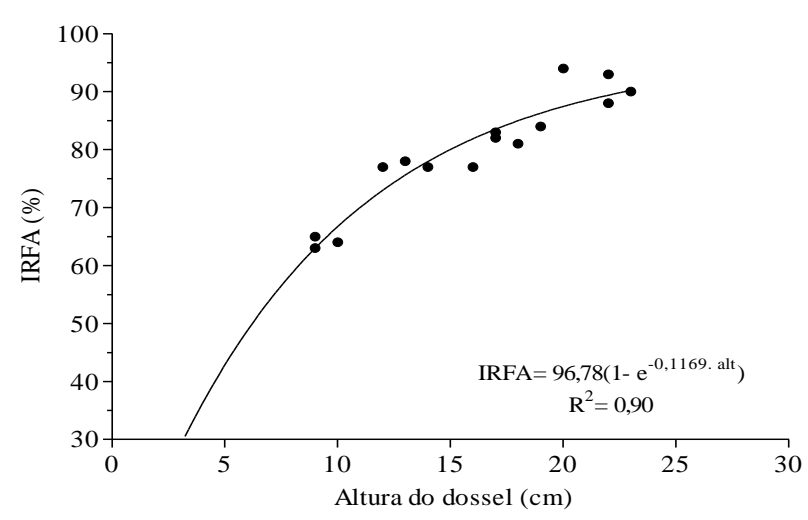

A altura do dossel é uma medida de fácil obtenção e a tentativa de relacioná-la com a IRFA pode facilitar atividades práticas de manejo das pastagens. A IRFA máxima do capim-braquiária decumbens encontrada neste trabalho de $94,0 \%$ foi alcançada em $20,0 \mathrm{~cm}$ de altura do dossel. A altura para interceptação dos $95 \%$ da RFA pôde ser estimada pela equação e o valor obtido foi de $24,3 \mathrm{~cm}$. O habito de crescimento decumbente do capim-braquiária decumbens proporciona a interceptação de $95 \%$ da RFA e portanto o momento de interrupção do processo de rebrotação em altura inferior quando comparada com outras espécies de Brachiaria de hábito de crescimento ereto ou cespitoso.

Figura 6. Relação entre altura do dossel e índice de área foliar em capim-braquiária decumbens.

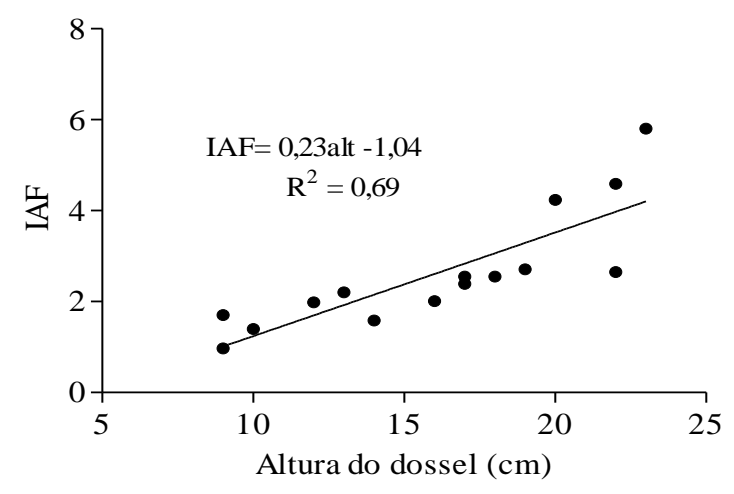

Galzerano et al. (2010) em trabalho com Brachiaria Brizantha cv. Xaraés sob cortes encontraram valores de altura do dossel superiores ao encontrado neste estudo. O valor de altura do dossel do capim- 
braquiária decumbens neste estudo também foi inferior ao encontrado por Pedreira et al. (2007), em trabalho com Brachiaria brizantha cv. Xaraés sob estratégias de pastejo rotativo, que registraram a altura do dossel de 29,5cm, aos 22 dias de crescimento pós-pastejo para o capim interceptar 95\% da RFA. Esses resultados demonstram que mesmo entre gramíneas forrageiras de mesma espécie, há que se estudar o melhor momento para interrupção da rebrota tanto em estratégias de corte como em pastejo.

\section{CONCLUSÃO}

A altura do dossel se correspondente positivamente com a interceptação da radiação fotossinteticamente ativa e o índice de área foliar em gramíneas forrageiras.

\section{REFERÊNCIAS}

BROUGHAM, R.W. Interception of light by the foliage of pure and mixed stands of pasture plants. Australian Journal of Agricultural Research, v. 9, p. 39-52, 1958.

BROWN, R. H.; BLASER, R. E. Leaf area index in pasture growth. Herbage Abstracts. v. 38, n. 1, p. 19, 1968.

CÂNDIDO, M. J. D. ALEXANDRINO, E. GOMIDE, J. A. M. Duração do período de descanso e crescimento do dossel de Panicum maximum cv. Mombaça sob lotação intermitente. Revista Brasileira de Zootecnia, v. 34, n. 2, p. 398 - 405, 2005.

CUNHA, F. F.; SOARES, A. A.; PEREIRA, O. G. et al. Características morfogênicas e perfilhamento do Panicum maximum Jacq. cv. tanzânia irrigado. Ciência e Agrotecnologia, v. 31, n. 3, p. 628-635, 2007.

EMPRESA BRASILEIRA DE PESQUISA AGROPECUÁRIA. Sistema Brasileiro de Classificação de Solos. Brasília: EMBRAPA, 2006. 306p.

FAGUNDES, J. L.; DA SILVA, S. C.; PEDREIRA, C. G. S. et al. Índice de área foliar, interceptação luminosa e acúmulo de forragem em pastagens de Cynodon spp. sob diferentes intensidades de pastejo. Scientia Agricola, v. 56, n. 4, p. 1141-1150, 1999.

GALZERANO, L.; MALHEIROS, E. B.; RUGGIERI, A. C. et al. Desenvolvimento das características do dossel do capim-xaraés e suas inter-relações. Scientia Plena, v. 7, n. 11, p. 1-5, 2011.

GALZERANO, L.; MALHEIROS, E. B.; RAPOSO, E. et al. Altura e interceptação de luz em dosséis de capim Xaraés sob corte. In: XX congresso Brasileiro de Zootecnia, Palmas. Anais..... Palmas, p. 1-3, 2010 .

GALZERANO, L.; ROSSIELLO, R. O. P.; OLIVEIRA, A. P. P. et al. Mudanças em atributos estruturais de dosséis do capim-tifton 85 na fase de estabelecimento, induzidas pela adubação nitrogenada. Boletim de Indústria Animal, v. 65, n. 4, p. 329-336, 2008.

PAULINO, V. T.; TEIXEIRA, E. M. L. Sustentabilidade de pastagens - manejo adequado como medida redutora da emissão de gases de efeito estufa. CPG- Produção animal sustentável, Ecologia de Pastagens, IZ, APTA/SAA, 2009. 16p. 
PEDREIRA, B. C.; PEDREIRA, C. G. S.; SILVA, S. C. Estrutura do dossel e acúmulo de forragem de Brachiaria brizantha cultivar Xaraés em resposta a estratégias de pastejo. 2007, pp. 281-287. Pesquisa Agropecuária Brasileira, v. 42, n. 2, p. 281-287, 2007.

PINTO, L. F. M.; SILVA, S. C.; SBRISSIA, A. F. et al. Dinâmica do acúmulo de matéria seca em pastagens de tifton 85 sob pastejo. Scientia Agricola, v. 58, n. 3, p.439- 447, 2001.

RHODES, I. The relationship between productivity and some components of canopy structure in ryegrass (Lolium spp.) II. Yield, canopy structure and light interception. Journal of Agriculture Science, v. 77, p. 283-292, 1971.

SILVA, V. C. Morfogênese, estrutura e dinâmica de perfilhamento de capim-tanzânia manejado com diferentes IAF residual, sob pastejo de cabras Anglonubiano. 2011. 65f. Dissertação (Mestrado em Zootecnia) - Faculdade de Ciências Agrárias e Veterinárias, Universidade Estadual Paulista "Júlio de Mesquita Filho". Jaboticabal.

SILVA, W. L. Morfogênese, características estruturais e acúmulo de forragem em pastos de capimtifton-85 manejados com diferentes IAF residual. 2010. 74f. Dissertação (Mestrado em Zootecnia) Faculdade de Ciências Agrárias e Veterinárias, Universidade Estadual Paulista "Júlio de Mesquita Filho". Jaboticabal, 2010.

'T MANNETJE, L. Advances in grassland science. Netherlands Journal of Agricultural Science. v. 50, n. 2, p. 195-221, 2002.

VILELA, D. Potencial das pastagens de Cynodon na pecuária de leite. In: VILELA, D.; RESENDE, J. C.; LIMA, J (Ed.). Cynodon, forrageiras que estão revolucionando a pecuária brasileira. 1. ed. Juiz de Fora: Ed. Embrapa Gado de Leite, Brasil, 2005, p.165-176.

VILELA, D.; ALVIM, M. J. Manejo de pastagens do gênero Cynodon: Introdução, caracterização e evolução do uso no Brasil. In: SIMPÓSIO SOBRE MANEJO DA PASTAGEM, 15, Piracicaba, 1998. Anais... Piracicaba: FEALQ, p. 23-54, 1998.

WATSON, D. J. Comparative physiological studies on the growth of field crops. t. Variation in net assimilation rate and leaf area between species and varieties, and within and between years. Annals of Botany... v. 2, p. 41-76, 1947. 